\title{
A Case of Duplicated Origin of the Left Vertebral Artery: CTA and MRA
} Findings and Literature Review

\author{
Seung Eun Lee, ${ }^{1}$ and Young-Seon Kim ${ }^{1, *}$
}

${ }^{1}$ Department of Radiology, College of Medicine, Yeungnam University, Daegu, Korea

"Corresponding author: Young-Seon Kim, Department of Radiology, College of Medicine, Yeungnam University, 170, Hyeonchung-ro, Nam-gu, Daegu, Korea. Tel: +82-26204129, Fax: +53-6535484, E-mail: ing29@hanmail.net

Received 2016 November 29; Accepted 2017 April 24.

\begin{abstract}
Duplication of the vertebral artery (VA) is rare but clinically significant. This variant shows a dual origin of VA with fusion at variable levels in the neck. It can be misdiagnosed as a dissection of the VA, arterial hypoplasia, or narrowing on selective catheter angiography. Thorough knowledge of this variation before an endovascular procedure is helpful in preventing unintentional diagnostic or therapeutic challenges. We report a case of a 52-year-old female patient with left duplicated VA, which was incidentally detected by magnetic resonance angiography (MRA) and contrast-enhanced computed tomography angiography (CTA). We have also reviewed the literature and discussed the embryological development of duplicated VA. This report can be helpful in identifying unexpected vascular variations on CTA or MRA and differentiate this anatomical variation from other pathologic conditions in clinical practice such as dissection, arterial hypoplasia, or arterial narrowing.
\end{abstract}

Keywords: Vertebral Artery, Duplication, Multidetector Computed Tomography, Magnetic Resonance Angiography

\section{Introduction}

The vertebral arteries (VAs) are among the major arteries of the neck. They supply blood to the upper spinal cord, brainstem, cerebellum, and posterior part of brain as the vertebrobasillar system. Anatomically, they usually arise from the first part of the subclavian arteries. There are variable developmental variations in the origin of the VA; these variations are associated with diverse clinical manifestations. Duplication of the VA is very rare; its incidence was only $0.164 \%$ in a recent large-scale study involving the Chinese population (1). This variant shows a dual origin of VA with fusion at variable levels in the neck (2). This condition can be misdiagnosed as a dissection of the VA, arterial hypoplasia, or arterial narrowing on selective catheter angiography $(3,4)$. A complete understanding of the variations in vertebral arteries is important for performing angiography or vascular interventional surgery. In this study, we present a case of left VA duplication in a patient who presented with dizziness. The left VA duplication was detected on both magnetic resonance angiography (MRA) and computed tomography angiography (CTA) examinations. We have also reviewed the embryological significance of and previous literature regarding this condition.

\section{Case Presentation}

A 52-year-old woman presented with a two-week history of headache and dizziness. The patient showed no other clinical abnormality or significant past medical history. She underwent brain magnetic resonance imaging (MRI) with 3D time-of-flight (TOF) intracranial MRA and gadolinium-enhanced neck MRA using a 1.5-Tesla system (Intera, Philips Medical Systems, Best, The Netherlands) and contrast enhanced computed tomography angiography (CTA) of the neck using a 128-slice CT scanner (SOMATOM Definition AS+, Siemens Healthcare, Forchheim, Germany). No abnormal focal lesion in the brain parenchyma was observed on routine brain MRI. Intracranial vessels observed on 3D TOF MRA were also normal. The dual origin of the left VA was noted on contrast enhanced MRA and CTA of the neck were demonstrated a dual origin of the left vertebral artery (Figure 1). The medial limb and lateral limb of the left VA were noted to originate from the left aortic arch and left subclavian artery, respectively. After their origins, the medial limb looped slightly forwards and ascended behind the left common carotid artery, while the lateral limb looped slightly poster laterally and ascended behind the medial limb. They united to form a single main trunk at the level of the $\mathrm{C} 5$ - 6 disk (about $5.6 \mathrm{~cm}$ from the medial orifice and $3.4 \mathrm{~cm}$ from the lateral orifice). The di- 

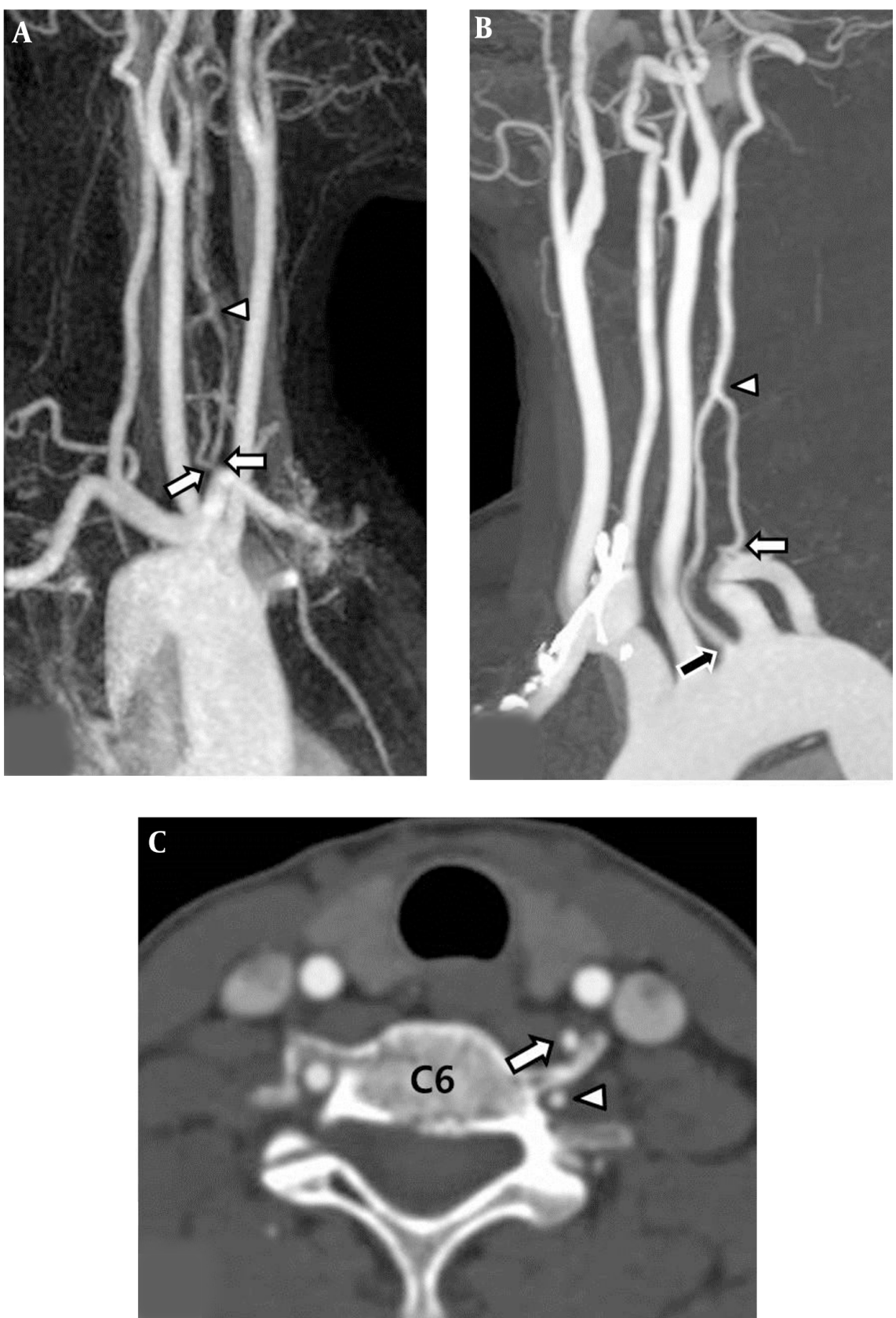

Figure 1. A 52-year-old woman with left duplicated vertebral artery. A, Three dimensional time-of-flight magnetic resonance angiography (3D TOF MRA) of right oblique view shows the double origin (arrows) of the left vertebral artery. Two limbs of the left' vertebral artery (VA) fused to form the distal part of the left VA (arrowhead). B, Contrastenhanced computed tomography angiography (CTA) maximum intensity projection image demonstrated the dual origin of the left vertebral artery. The medial limb originated from the left aortic arch (black arrow) and lateral limb originated from the left subclavian artery (white arrow). The two limbs united to form one main trunk (arrow head). C, Axial source image of CTA demonstrated a medial limb (arrow) originated from the aortic arch and a lateral limb (arrowhead) originated from the left subclavian artery at the $\mathrm{C} 6$ vertebra level.

ameters of the medial and lateral limbs at the points of origin were $2.3 \mathrm{~mm}$ and $2.0 \mathrm{~mm}$, respectively. The diameter of the distal common trunk of the left VA was $3.0 \mathrm{~mm}$ at the anastomosis of the two limbs (C5-6 disk level). The diame- ter of the right VA at the same level (C5 - 6 disk level) was $3.4 \mathrm{~mm}$. The patient's symptoms were relieved following conservative management. 
Table 1. Cases of Duplicated Origin of the Vertebral Artery Proved by Imaging Modality Since 2000

\begin{tabular}{|c|c|c|c|c|c|c|c|}
\hline Author, $Y /$ ref & Age & Sex & Laterality & Level of Union & Imaging Modality & Symptom & $\begin{array}{c}\text { Disease or Clinical } \\
\text { Status }\end{array}$ \\
\hline \multirow{2}{*}{$\begin{array}{l}\text { Goddard et al. (2001) } \\
\text { (2) }\end{array}$} & 66 & $\mathrm{~F}$ & Right & $\begin{array}{l}\text { Level of carotid } \\
\text { bifurcation }\end{array}$ & MRA, DSA & $\begin{array}{l}\text { Dysarthria, hemisensory } \\
\text { disturbance, hemiplegia }\end{array}$ & Cerebral infarction \\
\hline & 49 & M & Right & $\begin{array}{l}\text { Level of carotid } \\
\text { bifurcation }\end{array}$ & MRA & None & ICA occlusion \\
\hline $\begin{array}{l}\text { Ionete C. et al. (2006) } \\
(5)\end{array}$ & 83 & M & Bilateral & Right: C4 - 5, Left: C5 - 6 & MRA & Cognitive impairment & None \\
\hline \multirow{2}{*}{$\begin{array}{l}\text { Satti SR. et al. (2007) } \\
\text { (11) }\end{array}$} & 53 & $\mathrm{~F}$ & Right & $\mathrm{C} 3$ & DSA & Headache & Aneurysm \\
\hline & 62 & M & Left & $\mathrm{C} 7$ & DSA & Presyncope & None \\
\hline $\begin{array}{l}\text { Thomas et al. (2008) } \\
\text { (3) }\end{array}$ & 49 & $\mathrm{~F}$ & Right & C6 & DSA & None & Aneurysm \\
\hline $\begin{array}{l}\text { Harnier et al. (2008) } \\
\text { (12) }\end{array}$ & 61 & $\mathrm{~F}$ & Right & Not mentioned & MRA & Dizziness & None \\
\hline $\begin{array}{l}\text { Mordasini P. et al. } \\
(2008)(13)\end{array}$ & 48 & M & Bilateral & Bilateral, C4- 5 & MRA & Not mentioned & Cerebral infarction \\
\hline $\begin{array}{l}\text { Kim DW et al. (2009) } \\
(14)\end{array}$ & 42 & $\mathrm{~F}$ & Left & $\mathrm{C} 5$ & DSA & $\begin{array}{l}\text { Weakness, hemisensory } \\
\text { disturbance }\end{array}$ & AVF \\
\hline $\begin{array}{l}\text { Kendi ATK et al. (2009) } \\
\text { (6) }\end{array}$ & 59 & $\mathrm{~F}$ & Left & C5- 6 & CTA & Headache & Aneurysm \\
\hline \multirow{3}{*}{ Meila et al. (2012) (8) } & 54 & $\mathrm{~F}$ & Right & $\mathrm{C} 4$ & CTA & Not mentioned & None \\
\hline & 43 & $\mathrm{~F}$ & Bilateral & $\mathrm{C} 4$ & CTA & Severe headache & $\begin{array}{l}\text { Subarachnoid } \\
\text { hemorrhage }\end{array}$ \\
\hline & 56 & $\mathrm{~F}$ & Left & $\mathrm{C} 5$ & CTA & Not mentioned & Aneurysm \\
\hline Melki et al. (2012) (15) & 51 & M & Right & $\mathrm{C} 5-6$ & CTA, MRA & Acute vertigo & Cerebellar infarction \\
\hline Polguj et al. (2013) (7) & 43 & M & Left & C5 - 6 & CTA & $\begin{array}{l}\text { Headache, left limb } \\
\text { weakness }\end{array}$ & Right ICA dissection \\
\hline $\begin{array}{l}\text { Shin SW et al. (2013) } \\
\text { (16) }\end{array}$ & 51 & $\mathrm{~F}$ & Left & $\mathrm{C} 4$ & CTA, MRA, DSA & None & Aneurysm \\
\hline $\begin{array}{l}\text { Rameshbabu et al. } \\
(2014)(9)\end{array}$ & 36 & M & Right & $\mathrm{C} 4-5$ & CTA & Dizziness & None \\
\hline Baik JY et al. (2016) (17) & 69 & $\mathrm{~F}$ & Right & Not mentioned & MRA & Headache & None \\
\hline $\begin{array}{l}\text { Jung SG et al. (2016) } \\
\text { (18) }\end{array}$ & 63 & $\mathrm{~F}$ & Left & $\mathrm{C} 4$ & DSA & Vertigo & Cerebellar infarction \\
\hline Our case & 52 & $\mathrm{~F}$ & Left & C5- 6 & CTA, MRA & Headache, dizziness & None \\
\hline
\end{tabular}

Abbreviations: AVF, arteriovenous fistulas; CTA, computed tomography angiography; DSA, digital subtraction angiography; ICA, internal carotid artery; MRA, magnetic resonance angiography.

\section{Discussion}

Fenestration and duplication of the vertebral arteries are considered as developmental anomalies (5). The term "fenestration" refers to two parallel segments of the VA with a single origin, while the term "duplication" refers to a VA that has two origins with fusion at various levels in the $\operatorname{neck}(5,6)$.

Embryologically, the VAs typically originate from the distal ends of the seventh dorsal intersegmental arteries. The longitudinal anastomoses between the cervical intersegmental arteries form the VAs. The intersegmental arter- ies eventually regress, except the seventh, which becomes the proximal subclavian artery (SCA) containing the origin of the VA. Persistence of the intersegmental artery and abnormal development of the aortic arch can cause duplication of the VA (7). Persistence of the right fourth or fifth intersegmental arteries leads to a dual origin of the VA from the SCA or brachiocephalic trunk on the right side, or an aortic or a dual origin of the VA on the left side (4). The level of entrance into the transverse foramen indicates the intersegmental artery that persists (8).

Duplicated VAs are rarely reported in the literature. 
Komiyama et al. reviewed 26 cases of duplicated VAs reported before 1999 (4). Since 2000 , we found 20 additional cases (including our case) of duplicated VAs confirmed by an imaging modality (Table 1). Overall, 22 cases had a left duplicated VA and 21 cases had a right duplicated VA. Three patients had duplicated VA on both sides. In most cases, the medial limb originated from the aorta and the lateral limb originated from the subclavian artery. Either limb of the duplicated artery may also arise from the common carotid artery, brachiocephalic trunk, or thyrocervical trunk $(4,9)$. The fusion levels varied from C3 to C7 (Table 1).

The clinical presentation of duplicated VA is nonspecific; most of the reported cases are incidental findings in autopsy series, angiography, or MRA studies $(1,2,5)$. However, anecdotal reports suggest that this vascular anomaly may be a predisposing factor to VA dissection, intracranial aneurysm, kinking, and arteriovenous malformation (9). Whether the duplicated VA is associated with other pathologic conditions is still matter of debate.

Recognizing duplication of the VA is important in several clinical situations. First, a duplicated VA can mimic a VA dissection when a filling defect is created at the union of the two limbs, due to the mixing of contrast-containing blood from one limb and non-contrast- containing blood from the other limb during angiography (10). Second, an abrupt change in the diameter of the duplicated VA may occur at the level of the anastomosis. This might be confused with hypoplasia or pathologic narrowing of the vessel. In addition, the smaller lumen of the duplicated VA can influence the selection of the route for endovascular treatment $(3,5)$.

Complete knowledge of the vessel anatomy and variations is important during diagnostic and interventional angiography, to prevent unintentional diagnostic or therapeutic challenges. This report can be helpful in identifying unexpected vascular variations on CTA or MRA and differentiate this anatomical variation from other pathologic conditions in clinical practice such as dissection, arterial hypoplasia, or arterial narrowing.

\section{Acknowledgments}

This retrospective study was approved by our institutional review board and the requirement for written informed consent was waived.

\section{Footnotes}

Authors' Contributions: Young-Seon Kim designed and drafted, revised the manuscript. Seung Eun Lee interpreted data and drafted the manuscript.
Financial Disclosure: There are no conflicts of interest to declare.

Funding/Support: There are no funding or support to declare.

\section{References}

1. Li S, Li Y, Bai M, Zhang C. Three-Dimensional Time-of-Flight Magnetic Resonance Angiography Detection of Duplication of the Vertebral Artery in a Large Chinese Population. Med Sci Monit. 2016;22:3771-7. [PubMed: 27749814].

2. Goddard AJ, Annesley-Williams D, Guthrie JA, Weston M. Duplication of the vertebral artery: report of two cases and review of the literature. Neuroradiology. 2001;43(6):477-80. [PubMed: 11465760].

3. Thomas AJ, Germanwala AV, Vora N, Prevedello DM, Jovin T, Kassam A, et al. Dual origin extracranial vertebral artery: case report and embryology. J Neuroimaging. 2008;18(2):173-6. doi: 10.1111/j.15526569.2007.00182.x. [PubMed: 18302642].

4. Komiyama M, Nakajima H, Yamanaka K, Iwai Y. Dual origin of the vertebral artery-case report. Neurol Med Chir (Tokyo). 1999;39(13):932-7. [PubMed: 10658455].

5. Ionete $\mathrm{C}$, Omojola MF. MR angiographic demonstration of bilateral duplication of the extracranial vertebral artery: unusual course and review of the literature. AJNR Am J Neuroradiol. 2006;27(6):1304-6. [PubMed: 16775285].

6. Kendi AT, Brace JR. Vertebral artery duplication and aneurysms: 64slice multidetector CT findings. Br J Radiol. 2009;82(983):216-8. doi: 10.1259/bjr/26005109. [PubMed: 19890113].

7. Polguj M, Podgorski M, Jedrzejewski K, Topol M, Majos A. Fenestration and duplication of the vertebral artery: the anatomical and clinical points of view. Clin Anat. 2013;26(8):933-43. doi: 10.1002/ca.22231. [PubMed: 23553773].

8. Meila D, Tysiac M, Petersen M, Theisen O, Wetter A, Mangold A, et al. Origin and course of the extracranial vertebral artery: CTA findings and embryologic considerations. Clin Neuroradiol. 2012;22(4):327-33. doi: 10.1007/s00062-012-0171-0. [PubMed: 22941252].

9. Rameshbabu C, Gupta OP, Gupta KK, Qasim M. Bilateral asymmetrical duplicated origin of vertebral arteries: Multidetector row CT angiographic study. Indian J Radiol Imaging. 2014;24(1):61-5. doi: 10.4103/0971-3026.130699. [PubMed: 24851007].

10. Nogueira TE, Chambers AA, Brueggemeyer MT, Miller TJ. Dual origin of the vertebral artery mimicking dissection. AJNR Am J Neuroradiol. 1997;18(2):382-4. [PubMed: 9111680].

11. Satti SR, Cerniglia CA, Koenigsberg RA. Cervical vertebral artery variations: An anatomic study. AJNR Am J Neuroradiol. 2007;28:976-80. [PubMed: 17494682].

12. Harnier S, Harzheim A, Limmroth V, Horz R, Kuhn J. Duplication of the common carotid artery and the ipsilateral vertebral artery with a fenestration of the contralateral common carotid artery. Neurol India. 2008;56:491-3. [PubMed: 19127056].

13. Mordasisni P, Schmidt F, Schroth G, Remonda L. Asymmetrical bilateral duplication of the extracranial vertebral arteries: Report of a unique case. Eur J Radiol Extra. 2008;67:e91-4. [PubMed: 19127056].

14. Kim DW. Concomitant dual origin and fenestration of the left vertebral artery resembling dissection. J Korean Neurosurg Soc. 2009;46:498-500. [PubMed: 20041064].

15. Melki E, Nasser G, Vandendries C, Adams D, Ducreux D, Denier C. Congenital vertebral duplication: A predisposing risk factor for dissection. J Neurol Sci. 2012;314:161-2. [PubMed: 22093143].

16. Shin SW, Park DW, Park CK, Lee YJ, Lee SR. Duplication of the left vertebral artery origin: A case report. J Korean SocRadiol. 2013;68:1-4. [PubMed: 22093143]. 
17. Baik J, et al. Duplication of the right vertebral artery: MRA find ings and review of the literature. SpringerPlus. 2016;5(1):1-4. [PubMed: 22093143].
18. Jung S, et al. Duplicated origin of the left vertebral artery: a case report and embryological review. Neurointervention. 2016;11(1):50-4. [PubMed: 22093143]. 